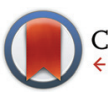

CrossMark \& click for updates

Cite this: Org. Chem. Front., 2016, 3 949

Received 11th May 2016,

Accepted 3rd June 2016

DOI: $10.1039 / \mathrm{c} 6 q 000194 \mathrm{~g}$

rsc.li/frontiers-organic

\title{
Convenient synthesis of pentafluoroethyl thioethers via catalytic Sandmeyer reaction with a stable fluoroalkylthiolation reagent $\dagger$
}

\author{
C. Matheis, \$ B. Bayarmagnai, \$ K. Jouvin and L. J. Goossen*
}

Aromatic and heteroaromatic diazonium salts were smoothly converted into the corresponding pentafluoroethyl thioethers by reaction with $\mathrm{Me}_{4} \mathrm{NSC}_{2} \mathrm{~F}_{5}$ in the presence of catalytic amounts of elemental copper. This Sandmeyer-type reaction proceeds at room temperature under mild conditions and is applicable to a wide range of functionalised molecules. It enables the late-stage introduction of pentafluoroethylthio groups, a promising but largely unexplored substituent, into bioactive molecules.

Fluorine-containing groups are of exceptional importance in modern bioactive molecules. Approximately $40 \%$ of currently marketed agrochemicals and $25 \%$ of pharmaceuticals contain fluorine atoms. ${ }^{1}$ The systematic introduction and screening of fluorinated residues has become a standard procedure in drug discovery. Thus, methods for the late-stage introduction of fluorinated substituents into functionalised molecules are highly sought-after. In the past decade, various powerful fluoroalkylation methods have been developed. ${ }^{2}$ The attention has recently shifted towards fluoroalkyl thioethers, since the $\mathrm{SCF}_{3}$ group induces even higher lipophilicity (Hansch constant 1.44 for $\mathrm{SCF}_{3}$ vs. 0.88 for $\mathrm{CF}_{3}$ ) and membrane permeability. ${ }^{3}$

Contemporary trifluoromethylthiolation reactions of arenes are based on electrophilic, ${ }^{4}$ nucleophilic, ${ }^{5}$ radical, ${ }^{6}$ or oxidative processes, ${ }^{7}$ usually starting from arylboronic acids or aryl halides.

Our contribution to the field of fluoroalkyl(thiol)ations has been the development of several Sandmeyer-type processes. ${ }^{8}$ We have demonstrated that a Sandmeyer-thiocyanation followed by a Langlois-type nucleophilic $\mathrm{CN}^{-\mathrm{CF}_{3}-}$ or $\mathrm{CF}_{2} \mathrm{H}^{-}$ exchange allows the convenient synthesis of fluoroalkylthioethers. ${ }^{8 f, 9}$ For laboratory-scale applications, the use of preformed reagents such as (bpy) $\mathrm{CuSCF}_{3},{ }^{10} \mathrm{AgSCF}_{3}{ }^{5 a}$ and $\mathrm{Me}_{4} \mathrm{NSCF}_{3}$ are more convenient. The bench-stable reagent $\mathrm{Me}_{4} \mathrm{NSCF}_{3}$ was first synthesised by Roeschenthaler and Yagupolskii ${ }^{11}$ and has successfully been employed in trifluoromethylthiolations of vinyl iodides, ${ }^{12}$ boronic acids,${ }^{7 d}$ aryl

FB Chemie-Organische Chemie, TU Kaiserslautern, Erwin-Schrödinger-Str. Geb. 54, D-67663 Kaiserslautern, Germany.E-mail: goossen@chemie.uni-kl.de;

Fax: +496312053921

$\dagger$ Electronic supplementary information (ESI) available. See DOI: 10.1039/ c6qo00194g

$\$$ These authors contributed equally to this work. halides, ${ }^{13}$ aryl triflates, ${ }^{14}$ and aryl $\mathrm{C}-\mathrm{H}$ bonds ${ }^{15}$ catalysed by $\mathrm{Cu}, \mathrm{Ni}$, or Pd complexes.

In medicinal chemistry, $\mathrm{C}_{2} \mathrm{~F}_{5}$ derivatives have repeatedly been found to exhibit properties that are superior to those of their $\mathrm{CF}_{3}$ counterparts. Whereas several methods have been reported for the introduction of pentafluoroethyl groups, there are only few reports on the corresponding pentafluoroethylthio compounds. ${ }^{16}$ Pentafluoroethyl thioarenes cannot be prepared by classical halogen/fluorine exchange reactions, e.g. Swartstype processes. Traditional syntheses of $\mathrm{SC}_{2} \mathrm{~F}_{5}$ moieties are based on the reaction of $\mathrm{C}_{2} \mathrm{~F}_{5}$ radicals or carbanions with disulfides or thiols. ${ }^{17}$ However, these methods suffer from harsh reaction conditions and limited availability of sulfur-containing substrates.

Modern methods suitable for the late-stage introduction of $\mathrm{SC}_{2} \mathrm{~F}_{5}$ groups include the Friedel-Crafts-type reaction of electron-rich arenes with a pentafluoroethyl sulfenamide reagent described by Billard et al. ${ }^{18}$ and the electrophilic perfluoroalkylthiolation of indoles with perfluoroalkyl sulfinate salts in the presence of stoichiometric copper chloride reported by Zhang et al. ${ }^{19}$ However, these methods are limited to electron-rich arenes and indoles. A generally applicable, regiospecific method for the introduction of $\mathrm{SC}_{2} \mathrm{~F}_{5}$ groups within a single step, based on widely available substrates and an inexpensive fluoroalkylation reagent, would be highly desirable.

We approached this challenge by investigating Sandmeyertype pentafluoroethylthiolations (Scheme 1). $\mathrm{Me}_{4} \mathrm{NSC}_{2} \mathrm{~F}_{5}$ appeared to be the reagent of choice, because according to a patent by Roeschenthaler, it is easily accessible from tetramethylammonium fluoride, elemental sulfur and $\mathrm{TMSC}_{2} \mathrm{~F}_{5} \cdot{ }^{11 a, 20}$

In order to probe the viability of our approach, we treated 4-methoxybenzenediazonium tetrafluoroborate with $\mathrm{Me}_{4} \mathrm{NSC}_{2} \mathrm{~F}_{5}$ in the presence of $10 \mathrm{~mol} \%$ CuSCN in acetonitrile at room temperature, conditions previously optimised for 
Traditional methods

This work

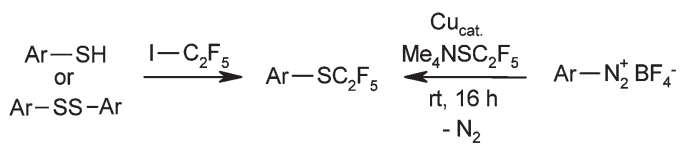

Scheme 1 Syntheses of pentafluoroethyl thioethers.

Sandmeyer trifluoromethylthiolations. ${ }^{8 e}$ The pentafluoroethyl thioether was indeed observed, albeit in unsatisfactory yield. The main products were 4-methoxyphenyl thiocyanate and the protodediazotisation product anisole (Table 1 , entry 1 ). It soon became clear that $\mathrm{C}_{2} \mathrm{~F}_{5} \mathrm{~S}^{-}$is substantially less nucleophilic than $\mathrm{SCF}_{3}{ }^{-}$, so that pentafluoroethylthiolation takes place only in reaction media free of other nucleophiles. Thus, most counter-ions of copper(I) precursors led to unwanted side product formation. However, the desired product was formed in high yield in the presence of elemental copper (entries 2-4).

The best results were obtained with $10 \mathrm{~mol} \%$ of $\mathrm{Cu}$ (entries 5-7). This is remarkable, since there are only few examples of Sandmeyer reactions catalytic in copper. The markedly lower nucleophilicity of the pentafluoroethylthio group in comparison to the trifluoromethylthio group is reflected in the increased reaction times; the pentafluoroethylthiolation requires 15 hours to go to completion, whereas Sandmeyer trifluoromethylthiolations occur within less than one hour at room temperature (entry 8). ${ }^{8 e}$ Without copper, no product formation was observed (entry 9).

Having thus found an effective protocol for the Sandmeyer pentafluoroethylthiolation, we next investigated its scope. Various arenediazonium tetrafluoroborates were smoothly converted into the corresponding pentafluoroethyl thioethers in high yields (Table 2).

Table 1 Optimisation of the reaction conditions ${ }^{a}$

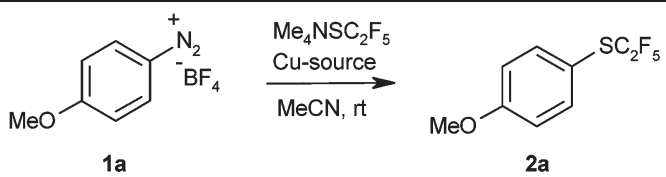

\begin{tabular}{lll}
\hline Entry & Cu-source & Yield 2a [\%] \\
\hline 1 & 10 mol\% CuSCN & 70 \\
2 & 10 mol\% CuOAc & 15 \\
3 & 10 mol\% CuI & 20 \\
4 & 10 mol\% Cu & 99 \\
5 & 5 mol\% Cu & 62 \\
6 & 0.5 equiv. Cu & 89 \\
7 & 1.0 equiv. Cu & 75 \\
$8^{b}$ & 1.0 equiv. Cu & 12 \\
9 & - & 0
\end{tabular}

${ }^{a}$ Reaction conditions: dropwise addition of $0.5 \mathrm{mmol}$ of $1 \mathrm{a}$ in $1 \mathrm{~mL}$ acetonitrile to 1.5 equiv. $\mathrm{Me}_{4} \mathrm{NSC}_{2} \mathrm{~F}_{5}$ and the copper source in $1 \mathrm{~mL}$ acetonitrile, $15 \mathrm{~h}$ at room temperature. Yields were determined by ${ }^{19} \mathrm{~F}$ NMR using trifluoroethanol as an internal standard. ${ }^{b} 1 \mathrm{~h}$ reaction time.
Table 2 Substrate scope of the Sandmeyer pentafluoroethylthiolation ${ }^{a}$

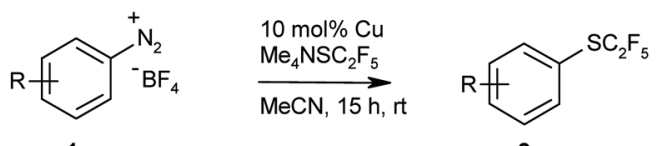

2<smiles>COc1ccc([Se]C(F)(F)F)cc1</smiles><smiles>Cc1cccc([AsH2+]C(F)(F)F)c1</smiles><smiles>FC(F)(F)c1ccc(-c2ccccc2)cc1</smiles>

2a $98 \%$

$2 b, 93 \%$

2c, $95 \%$<smiles>FC(F)(F)c1ccc(Oc2ccccc2)cc1</smiles><smiles>FC(F)(F)c1ccc(Br)cc1</smiles>

2e, $78 \%$<smiles>[X]c1ccc(S(F)(F)F)cc1</smiles>

$X=F 2 f, 61 \%[b]$ Cl 2g, $69 \%$<smiles>CC(=O)c1ccc([Ge](F)(C(F)(F)F)C(F)(F)F)cc1</smiles><smiles>O=C(c1ccccc1)c1ccc(C(F)(F)C(F)(F)F)cc1</smiles><smiles>COC(=O)c1ccc(C(F)(F)F)cc1</smiles><smiles>CN(C)c1ccc(S(F)(F)F)cc1</smiles><smiles>CC(=O)Nc1ccc(C(F)(F)F)cc1</smiles><smiles>O=[N+]([O-])c1ccc([As+](=O)[O-])cc1</smiles><smiles>N#Cc1ccc(S(F)(F)F)cc1</smiles><smiles>O=[N+]([O-])c1cc(C(C(F)(F)F)C(F)(F)F)cc2ccccc12</smiles><smiles>O=[P+]([O-])c1ccc(S(F)(F)F)cc1</smiles><smiles>FC(F)(F)[AsH2]c1cccc2cccnc12</smiles>

$2 q, 71 \%$<smiles>CCn1c2ccccc2c2cc(C(F)(F)F)ccc21</smiles>

2r, $72 \%$<smiles>COC(=O)c1sccc1C(F)(F)F</smiles>

2s, $98 \%$

${ }^{a}$ Reaction conditions: dropwise addition of $1.0 \mathrm{mmol}$ of 1 in $2 \mathrm{~mL}$ MeCN to $1.5 \mathrm{mmol} \mathrm{Me}_{4} \mathrm{NSC}_{2} \mathrm{~F}_{5}$ and $0.1 \mathrm{mmol}$ elemental copper in $2 \mathrm{~mL}$ MeCN, $15 \mathrm{~h}$ at room temperature. ${ }^{b}$ Yields determined by ${ }^{19} \mathrm{~F}$ NMR using trifluoroethanol as an internal standard.

Both electron-rich and electron-deficient substrates give similarly high yields, and various functionalities are tolerated including ester, ether, amino, keto, carboxylate, cyano, and even bromo groups. Various heterocycles were also pentafluoroethylthiolated in good yields. These examples clearly demonstrate the utility of the protocol for late-stage pentafluoroethylthiolations of functionalised intermediates. The products are obtained in reasonable purity after simple aqueous workup, and can be further purified by column chromatography.

It is safe to assume that in analogy to classical Sandmeyer halogenations and trifluoromethylthiolations of diazonium salts, the reaction proceeds via a single-electron transfer mechanism as depicted in Scheme 2. The use of metallic copper as source of $\mathrm{Cu}(\mathrm{I})$ species in these processes is rare but 


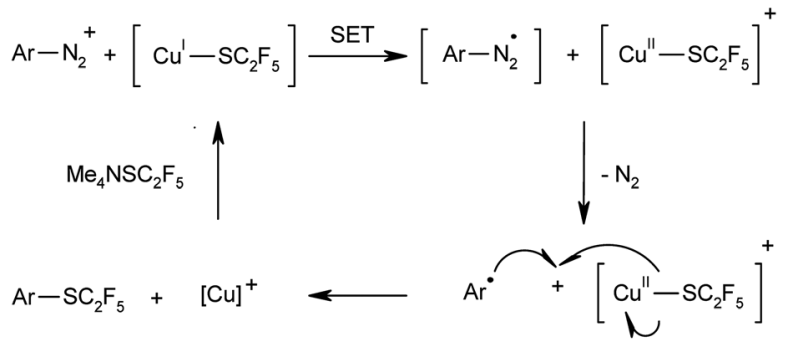

Scheme 2 Sandmeyer pentafluoroethylthiolation of aromatic amines.

not unprecedented. $^{8 e, 21}$ The addition of radical quenchers such as 2,2,6,6-tetramethylpiperidine- $N$-oxyl (TEMPO) or $p$-benzoquinone suppressed the reaction, which confirms that the reaction involves radical intermediates. In order to exclude an alternative cationic pathway for extremely electron-poor substrates, analogous control experiments were conducted with 4-nitrobenzenediazonium tetrafluoroborate. In the absence of copper or in the presence of radical trapping reagents no product formation was detected, which supports a Sandmeyer type mechanism even for substrates in which other pathways are conceivable.

\section{Conclusions}

The Sandmeyer-type process reported herein allows the straightforward synthesis of pentafluoroethylthiolated compounds from the corresponding aromatic amines. The key advantages of this method are its mild reaction conditions (neutral, room temperature), the use of an inexpensive copper catalyst in only $10 \mathrm{~mol} \%$ loading, and the exceptional functional group tolerance. As a result, this method is well-suited for the late-stage introduction of pentafluoroethylthio groups into drug-like molecules.

\section{Acknowledgements}

We thank the Heinrich-Böll-Stiftung e.V. (scholarship to B. B.) for financial support.

\section{References}

1 (a) J. Wang, M. Sánchez-Roselló, J. L. Aceña, C. del Pozo, A. E. Sorochinsky, S. Fustero, V. A. Soloshonok and H. Liu, Chem. Rev., 2014, 114, 2432-2506; (b) P. Jeschke, ChemBioChem, 2004, 5, 570-589; (c) W. K. Hagmann, J. Med. Chem., 2008, 51, 4359-4369.

2 (a) O. A. Tomashenko and V. V. Grushin, Chem. Rev., 2011, 111, 4475-4521; (b) T. Furuya, A. S. Kamlet and T. Ritter, Nature, 2011, 473, 470-477; (c) X.-F. Wu, H. Neumann and M. Beller, Chem. - Asian J., 2012, 7, 1744-1754; (d) T. Liu and Q. Shen, Eur. J. Org. Chem., 2012, 6679-6687; (e) T. Liang, C. N. Neumann and T. Ritter, Angew. Chem., Int. Ed., 2013, 52, 8214-8264; (f) X. Liu, C. Xu, M. Wang and Q. Liu, Chem. Rev., 2015, 115, 683-730; (g) C. Alonso, E. Martínez de Marigorta, G. Rubiales and F. Palacios, Chem. Rev., 2015, 115, 1847-1935.

3 (a) C. Hansch, A. Leo, S. H. Unger, K. H. Kim, D. Nikaitani and E. J. Lien, J. Med. Chem., 1973, 16, 1207-1216; (b) F. Toulgoat, S. Alazet and T. Billard, Eur. J. Org. Chem., 2014, 2415-2428.

4 (a) A. Tlili and T. Billard, Angew. Chem., Int. Ed., 2013, 52, 6818-6819; (b) X. Shao, X. Wang, T. Yang, L. Lu and Q. Shen, Angew. Chem., Int. Ed., 2013, 52, 3457-3460; (c) Y.-D. Yang, A. Azuma, E. Tokunaga, M. Yamasaki, M. Shiro and N. Shibata, J. Am. Chem. Soc., 2013, 135, 8782-8785; (d) R. Pluta, P. Nikolaienko and M. Rueping, Angew. Chem., Int. Ed., 2014, 53, 1650-1653; (e) C. Xu, B. Ma and Q. Shen, Angew. Chem., Int. Ed., 2014, 53, 93169320.

5 (a) G. Teverovskiy, D. S. Surry and S. L. Buchwald, Angew. Chem., Int. Ed., 2011, 50, 7312-7314; (b) C.-P. Zhang and D. A. Vicic, J. Am. Chem. Soc., 2012, 134, 183-185; (c) Z. Weng, W. He, C. Chen, R. Lee, D. Tan, Z. Lai, D. Kong, Y. Yuan and K.-W. Huang, Angew. Chem., Int. Ed., 2013, 52, 1548-1552.

6 L. D. Tran, I. Popov and O. Daugulis, J. Am. Chem. Soc., 2012, 134, 18237-18240.

7 (a) C. Chen, Y. Xie, L. Chu, R.-W. Wang, X. Zhang and F.-L. Qing, Angew. Chem., Int. Ed., 2012, 51, 2492-2495; (b) C. Chen, L. Chu and F.-L. Qing, J. Am. Chem. Soc., 2012, 134, 12454-12457; (c) C.-P. Zhang and D. A. Vicic, Chem. Asian J., 2012, 7, 1756-1758; (d) S.-Q. Zhu, X.-H. Xu and F.-L. Qing, Eur. J. Org. Chem., 2014, 4453-4456.

8 (a) B. Bayarmagnai, C. Matheis, E. Risto and L. J. Goossen, Adv. Synth. Catal., 2014, 356, 2343-2348; (b) G. Danoun, B. Bayarmagnai, M. Grünberg, C. Matheis, E. Risto and L. Gooßen, Synthesis, 2014, 2283-2286; (c) C. Matheis, K. Jouvin and L. J. Goossen, Org. Lett., 2014, 16, 5984-5987; (d) B. Bayarmagnai, C. Matheis, K. Jouvin and L. J. Goossen, Angew. Chem., Int. Ed., 2015, 54, 5753-5756; (e) C. Matheis, V. Wagner and L. J. Goossen, Chem. - Eur. J., 2016, 22, 79-82; $(f)$ G. Danoun, B. Bayarmagnai, M. F. Gruenberg and L. J. Goossen, Chem. Sci., 2014, 5, 1312-1316.

9 (a) B. Exner, B. Bayarmagnai, F. Jia and L. J. Goossen, Chem. - Eur. J., 2015, 21, 17220-17223; (b) K. Jouvin, C. Matheis and L. J. Goossen, Chem. - Eur. J., 2015, 21, 14324-14327; (c) C. Matheis, M. Wang, T. Krause and L. Goossen, Synlett, 2015, 26, 1628-1632.

10 (a) Z. Weng, W. He, C. Chen, R. Lee, D. Tan, Z. Lai, D. Kong, Y. Yuan and K.-W. Huang, Angew. Chem., Int. Ed., 2013, 52, 1548-1552; (b) C. Chen, Y. Xie, L. Chu, R.-W. Wang, X. Zhang and F.-L. Qing, Angew. Chem., Int. Ed., 2012, 51, 2492-2495; (c) Y. Zhang, K. Gan and Z. Weng, Org. Process Res. Dev., 2016, 20, 799-802.

11 (a) P. Kirsch, G. V. Roeschenthaler, B. Bissky and A. Kolomeitsev, DE-A1 10254597, 2003, Merck GmbH; 
(b) W. Tyrra, D. Naumann, B. Hoge and Y. L. Yagupolskii, J. Fluorine Chem., 2003, 119, 101-107.

12 M. Rueping, N. Tolstoluzhsky and P. Nikolaienko, Chem. Eur. J., 2013, 19, 14043-14046.

13 (a) G. Yin, I. Kalvet, U. Englert and F. Schoenebeck, J. Am. Chem. Soc., 2015, 137, 4164-4172; (b) G. Yin, I. Kalvet and F. Schoenebeck, Angew. Chem., Int. Ed., 2015, 54, 6809-6813; (c) Y. Yang, L. Xu, S. Yu, X. Liu, Y. Zhang and D. A. Vicic, Chem. - Eur. J., 2016, 22, 858863.

14 A. B. Dürr, G. Yin, I. Kalvet, F. Napoly and F. Schoenebeck, Chem. Sci., 2016, 7, 1076-1081.

15 C. Xu and Q. Shen, Org. Lett., 2014, 16, 2046-2049.

16 (a) M. Andrzejewska, Eur. J. Med. Chem., 2002, 37, 973-978; (b) A. Johansson, A. Poliakov, E. Åkerblom, K. Wiklund,
G. Lindeberg, S. Winiwarter, U. H. Danielson, B. Samuelsson and A. Hallberg, Bioorg. Med. Chem., 2003, 11, 2551-2568; (c) A. Lishchynskyi and V. V. Grushin, J. Am. Chem. Soc., 2013, 135, 12584-12587.

17 N. Roques, J. Fluorine Chem., 2001, 107, 311-314.

18 S. Alazet and T. Billard, Synlett, 2014, 76-78.

19 L. Jiang, J. Qian, W. Yi, G. Lu, C. Cai and W. Zhang, Angew. Chem., Int. Ed., 2015, 54, 14965-14969.

20 (a) P. Kirsch, Modern fluoroorganic chemistry: synthesis, reactivity, applications, Wiley-VCH, Weinheim, 2004, p. 145; (b) $\mathrm{Me}_{4} \mathrm{NSC}_{2} \mathrm{~F}_{5}$ was commercially available by CF Plus Chemicals s. r. o.

21 (a) N. Kornblum, G. D. Cooper and J. E. Taylor, J. Am. Chem. Soc., 1950, 72, 3013-3021; (b) C. Galli, Chem. Rev., 1988, 88, 765-792. 